\title{
A controllable gene-expression system for the pathogenic fungus Candida glabrata
}

\author{
Hironobu Nakayama, Miho Izuta, Shigehisa Nagahashi, Emi Y. Sihta, \\ Yasuko Sato, Toshikazu Yamazaki, Mikio Arisawa and Kunio Kitada
}

Author for correspondence: Hironobu Nakayama. Tel: +81 46747 2222. Fax: +81467465320.

e-mail: hironobu.nakayama@roche.com

Department of Mycology, Nippon Roche Research Center, 200 Kajiwara, Kamakura, Kanagawa 247, Japan

\begin{abstract}
A system for controlling gene expression was established in the pathogenic fungus Candida glabrata to elucidate the physiological functions of genes. To control the expression of the gene of interest, the $C$. glabrata cells were first transformed with the plasmid carrying the tetracycline repressortransactivator fusion tetR:: GAL4, then with the DNA fragment containing the controllable cassette, the tetracycline operator chimeric promoter (tetO:: ScHOP1). The peptide elongation factor 3 (CgTEF3) and DNA topoisomerase II (CgTOP2) genes from C. glabrata were cloned and their expression assessed using this system. When the promoter of CgTEF3 or CgTOP2 was replaced with tetO::SCHOP1, doxycycline almost completely repressed the expression of both mRNAs, and impaired growth. Repression of the TOP2 or TEF3 gene by doxycycline also hampered the survival of C. glabrata cells in mice; in mouse kidneys the number of $C$. glabrata cells, in which the TOP2 or TEF3 promoter was replaced with the tetO:: SCHOP1 controllable cassette, did not increase when the mice were given doxycycline. Thus, it appears that the gene repression mediated by doxycycline occurred not only in culture media but also in animals; therefore, this system can be used to elucidate the function of the gene in fungal infections and pathogenesis.
\end{abstract}

Keywords: Candida glabrata, gene expression, tetracycline-responsive element, peptide elongation factor 3, DNA topoisomerase II

\section{INTRODUCTION}

The incidence of fungal infections has been increasing, particularly in patients who are immunocompromised by HIV infection, and in patients who are receiving immunosuppressive therapy for organ transplantation or chemotherapy for cancer. Current therapies against pathogenic fungi rely mainly on two chemical groups: the polyenes, which disrupt membrane structure, and the azoles, which inhibit the synthesis of ergosterol (Gallis et al., 1990; Georgopapadakou \& Walsh, 1996). However, the toxicity of the polyenes and appearance of azole-resistant strains require the development of novel antifungal drugs (Gallis et al., 1990; Rex et al., 1995).

The recent release of the complete nucleotide sequence of Saccharomyces cerevisiae has allowed us to identify all the genes in this unicellular organism (Saccharomyces

Abbreviation: GAL4AD, GAL4 activation domain.

The DDBJ accession numbers for the sequences reported in this paper are $A B 012141$ and $A B 010644$ for CgTEF3 and CgTOP2 respectively.
Genome Database, Stanford University; The Munich Information Centre for Protein Sequences; Yeast Protein Database: Proteome); their physiological functions are currently being studied. A project to sequence the genome of the pathogenic fungus Candida albicans has been initiated. Among 6000 S. cerevisiae genes, approximately 600 have turned out to be essential for growth; deletion or disruption of any one of these genes is lethal. These essential genes are considered to be feasible antifungal targets, but such information alone is not sufficient to pinpoint the importance of the genes for infection, colonization, invasion and pathogenicity.

Unlike C. albicans, Candida glabrata always grows as a haploid yeast cell and does not form hyphae, which makes genetic manipulations easy. C. glabrata is phylogenetically similar to S. cerevisiae (Barns et al., 1991) and is an opportunistic pathogen (Aisner et al., 1976; Hickey et al., 1983). It causes mucocutaneous and systemic mycoses in immunocompromised patients who are treated with immunomodulators or anti-cancer drugs (Wingard, 1995). As seen in patients with $C$. 
albicans infection, extensive use of topical and systemic antifungal drugs has increased the incidence of mucousmembrane colonization and the appearance of azoleresistant C. glabrata (Hitchcock et al., 1993; Newman et al., 1994). Thus, C. glabrata seems to be a feasible model organism for establishing a system applicable to the functional analysis of fungal genes for infection and virulence.

We have established a system for controlling gene expression in $S$. cerevisiae by using the tetracyclineresponsive element (Nagahashi et al., 1997). In this study, this technique was applied to C. glabrata. The peptide elongation factor 3 (TEF3) and the DNA topoisomerase II (TOP2) genes were cloned from C. glabrata and their expression examined using this method. Because both TEF3 and TOP2 in S. cerevisiae have been shown to be essential (Sandbaken et al., 1990; Goto \& Wang, 1984); they are thought to be potential targets of antifungal drugs (Triana-Alonso et al., 1995; Figgitt et al., 1989; Shen et al., 1992). Here, we report the effects of the repression of TEF3 or TOP2 of C. glabrata on its growth in media and survival in mice. A role for these genes in systemic infections is proposed.

\section{METHODS}

Generation of the test strain and transactivator-expressing strains. The plasmid pINTG4 (Fig. 1a) was constructed by ligating the $2.0 \mathrm{~kb} S p b \mathrm{I}$ fragment containing the repressortransactivator fusion tetR::GAL4AD (GAL4 activation domain) from pINFAGAL4 (Nagahashi et al., 1997) and the $1.5 \mathrm{~kb} K p n \mathrm{I}$ fragment from pT2/SalI (Kitada et al., 1995) carrying the C. glabrata TRP1 gene (CgTRP1). pINTG4 was digested with EcoRV and used to transform the C. glabrata strains 2001HT (his3 trp1) and 2001HTU (his3 trp1 ura3) (Kitada et al., 1995). The resulting $\mathrm{TRP}^{+}$transformants, ACG4 (his3 trp1 PScHOP1::tetR::GAL4AD::TRP1) and ACG22 (bis3 ura3 trp1 PScHOP1::tetR:: GAL4AD::TRP1), constitutively expressed the tet $R:$ : GAL4AD fusion activator.

To generate the test strain, 97ScHIS3, p97tScHIS3U was constructed by introducing the $97 \mathrm{t}$ fragment, the ScHIS3 ORF and the CgURA3gene into pRS414 (Stratagene; cloned into the SacI/EcoRI sites, the EcoRI/SalI sites and the XboI site, respectively), which was used to transform ACG22 after being digested with XhoI at the $5^{\prime}$ flanking region of $C g U R A 3$. The $97 \mathrm{t}$ fragment was the $0.6 \mathrm{~kb}$ SacI-EcoRI fragment derived from p97tCC (Nagahashi et al., 1997). The ScHIS3 ORF was amplified by PCR from $S$. cerevisiae genomic DNA using primers HIS01 and HIS02 (Table 1), and the CgURA3 gene was amplified from C. glabrata genomic DNA using primers PCGURA5 and PCGURA3 (Table 1).

Cloning the TEF3 and TOP2 genes of C. glabrata. An approximately $0.6 \mathrm{~kb}$ fragment of $C g T E F 3$ was amplified from C. glabrata genomic DNA by PCR, using primers YEF32373 and YEF3-2996 (Table 1), which were designed based on the sequence of the $S$. cerevisiae YEF3 gene, encoding peptide elongation factor 3 . The amplified fragment was cloned in pT7blue (Novagen). Because Southern blot analysis of $C$. glabrata genomic DNA using the above PCR fragment as a probe revealed that a BamHI fragment of about $9 \mathrm{~kb}$ strongly hybridized with the fragment, a C. glabrata genomic DNA library, which contained mainly $9 \mathrm{~kb}$ BamHI fragments, was generated using pBluescript II SK+ (Stratagene). The full- (a)
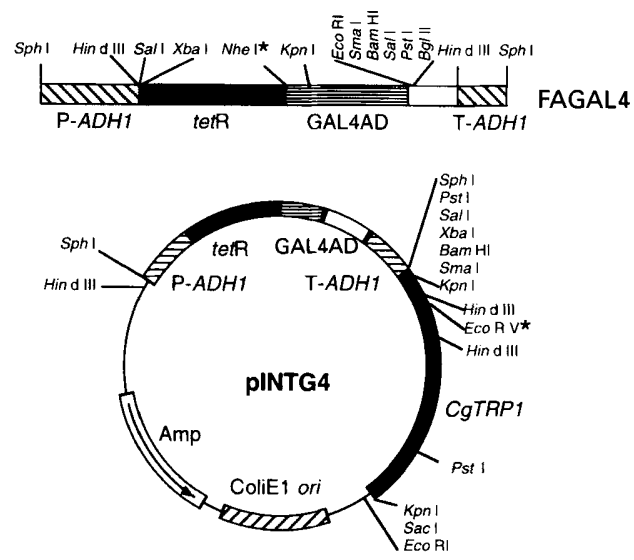

(b)
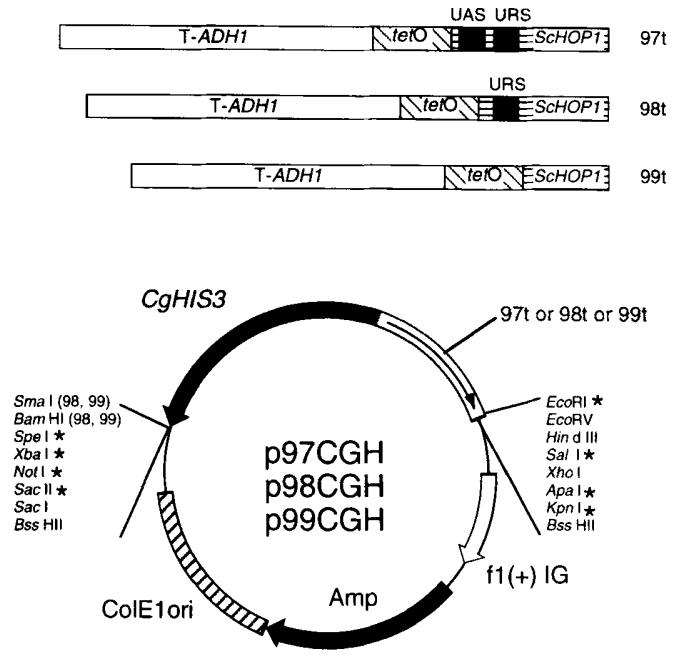

Fig. 1. Plasmid construction. (a) Schematic representation of the fusion transactivator tetR::GAL4 and integration vector pINTG4. The ECORV site (marked with an asterisk), which is located in the $3^{\prime}$ region of CgTRP1, was used for the linearization of the plasmid. (b) Schematic representation of the controllable promoters and the plasmid carrying a controllable cassette. The black boxes in the SCHOP1 region represent upstream activator (UAS) or upstream repressor (URS) sequences. These plasmids were derivatives of p97tCC, p98tCC and p99tCC (Nagahashi et al., 1997). Unique restriction sites in these plasmids are marked with asterisks.

length $T E F 3$ gene was identified from the library by screening with the above PCR fragment. Genomic DNA was extracted from the C. glabrata strain ATCC 2001 as described by Rose et al. (1990).

To isolate the TOP2 gene from C. glabrata, we used the $S$. cerevisiae temperature-sensitive mutant SD 1-4 [MATa ade1 ade2 ura3-52 top2-1(ts)] (DiNardo et al., 1984) for the functional screening. Another C. glabrata genomic DNA library was constructed by ligating $5-10 \mathrm{~kb}$ fragments of $C$. glabrata genomic DNA, that had been partially digested with Sau3AI, into the BamHI site of pRS416 (Stratagene). After transforming the SD 1-4 cells, with the above DNA library, the cells that grew at a non-permissive temperature $\left(37^{\circ} \mathrm{C}\right)$ were collected and the plasmid, which reproducibly supported the growth of SD $1-4$ cells at $37^{\circ} \mathrm{C}$ were recovered. 
Tab/e 1. Primers used in this study

\begin{tabular}{|c|c|c|}
\hline Name & Sequence $\left(5^{\prime}-3^{\prime}\right)$ & $\begin{array}{l}\text { Introduced } \\
\text { site }\end{array}$ \\
\hline HIS01 & GGCCGAATTCGCAAAGATGACAGAGCAG & EcoRI \\
\hline HISO2 & GGCCGTCGACCCGTTCCTCCATCTCTT & SalI \\
\hline PCGURA5 & CCACACGTCGACCCATAAGAGAGGTCAAGG & Sall \\
\hline PCGURA3 & AATCTGTCGACTAGAAGTCAGACGCTTGCC & Sall \\
\hline CGHIS5EV & TTTTTTGATATCTGGCCCGAGTCACC & EcoRV \\
\hline CGHIS3SM & GGCCGGCCCGGGACAAGCTCATCGCCC & Smal \\
\hline YEF3-2373 & GTAAGTTGGTCGAAG & - \\
\hline YEF3-2996 & CATCAACTTGACCGTTGGC & - \\
\hline TEF3AF & TTTTTTGAGCTCTGGTATTGGTGTTGAGCC & SacI \\
\hline TEF3AR & TTTTTTCCCGGGTGGATTAGAATATTGTTTAGCTTG & SmaI \\
\hline TEF3BF & TTTTTTGAATTCTGAATGACTGACTCT & EcoRI \\
\hline TEF3BR & TTTTTTCTCGAGATCCAAGACGTCCTTGGCG & Xhol \\
\hline C5TEF3 & GAGACGTAAGGACGACCAC & - \\
\hline C3TEF3 & GATCATTTCTTCAGTGAAACCG & - \\
\hline CGTOPA & $\begin{array}{l}\text { GTGAGTTCAGGCAAGAAGTAGATCCTACGCGCTC } \\
\text { AATTAGGAAAGCAAAATTGACGTGGGCCCGGGAC } \\
\text { AAGCTCATCG }\end{array}$ & - \\
\hline CGTOPB & $\begin{array}{l}\text { AATATGCTCTAACTGAGATATCTTCTGATATCTTTC } \\
\text { AGAAGCGGTTTTAGGTTCACTCATTTGAACGAATT } \\
\text { CTTTTCTGAGATAAAGC }\end{array}$ & - \\
\hline P5TOP2 & TTGATAGAATTCGTTCAAATGAGTGAACCTAAAAC & EcoRI \\
\hline P3TOP2 & TCATCAGTCGACTTCGAAAACGTCAACAAGTGTCC & SalI \\
\hline C5TOP2 & GGGAAAATCGAGTTGTGATTTG & - \\
\hline C3TOP2 & GGCGGATGACACACATTC & - \\
\hline P5ERG11 & TTTTTTGAATTCAATAACATGTCCACTGAAAAC & EcoRI \\
\hline P3ERG11 & TTTTTTGTCGACGTGACCCTTTGGACCCAAG & SalI \\
\hline
\end{tabular}

Generation of strains containing the TEF3 and TOP2 controllable cassettes. The plasmids p97CGH, p98CGH and p99CGH (Fig. 1b) were generated by replacing $S c U R A 3$ cloned in p97tCC, p98tCC or p99tCC (Nagahashi et al., 1997) with the C. glabrata HIS3 (CgHIS3) gene. These plasmids comprise the $S c H O P 1$ promoter derivatives. p97 has both the upstream activation sequence (UAS; nt -198 to -190 in the ScHOP1 gene) and the upstream repression sequence (URS; nt -173 to -165 in the ScHOP1 gene), p98 carries only the URS region and p99 harbours no UAS or URS (Vershon et al., 1992; Fig. 1 b). The $\mathrm{CgHIS} 3$ gene was amplified from C. glabrata genomic DNA by PCR using primers CGHIS5EV and CGHIS3SM (Table 1).

Region A (nt -598 to -234 ) or region B (nt -6 to +1215 ) of CgTEF3 (see Fig. 2) was amplified with PCR using primers TEF3AF and PTEF3AR, or TEF3BF and TEF3BR, respectively. For the homologous recombination, the $\mathrm{A}$ and $\mathrm{B}$ regions of $\mathrm{CgTEF} 3$ were cloned into the $\mathrm{Sacl} / \mathrm{Smal}$ sites (for region A) and EcoRI/Xhol sites (for region B) of p97CGH, 98CGH and 99CGH, generating p97TEF3, p98TEF3 and p99TEF3, respectively. These three plasmids were linearized with BssHII and were used to transform ACG4; two strains, 98TEF3 and 99TEF3, were obtained. For TOP2, the controllable cassettes carrying the $\mathrm{A}$ and $\mathrm{B}$ regions of $\mathrm{Cg} T O P 2$ were amplified from p97CGH, p98CGH, or p99CGH by PCR using the primers CGTOPA and CGTOPB. These primers include part of the sequence of the C. glabrata TOP2 gene (CgTOP2) (CGTOPA contains $n t-149$ to -89 and CGTOPB includes nt -6 to +60 of $\mathrm{CgTOP2}$ ) and part of p97CGH, p98CGH and p99CGH. These three controllable cassettes were used to transform ACG4; the resulting strains were designated 97TOP2, 98TOP2 and 99TOP2, respectively. All the synthetic oligonucleotides used for PCR are listed in Table 1.

Southern and Northern blot analyses. Ten micrograms of genomic DNA from C. glabrata ATCC 2001 was digested with restriction endonucleases and separated on an agarose gel. The DNA was transferred to a nylon membrane (Hybond$\mathrm{N}^{+}$, Amersham), hybridized with the radiolabelled probe and visualized by autoradiography or by image analyser BAS1000 (Fuji).

Total RNA was extracted by the glass-bead lysis method (Rose et al., 1990). Approximately $10 \mu \mathrm{g}$ total RNA was separated on an agarose gel, transferred onto a nylon membrane (Hybond-N, Amersham) and hybridized with radiolabelled probes. DNA fragments used for hybridization were the $0.5 \mathrm{~kb} E c o \mathrm{RV}-E c o \mathrm{RV}$ fragment of CgTEF3, the $0.4 \mathrm{~kb}$ fragment of CgTOP2 ( $\mathrm{nt}-6$ to +394 ) and the $0.3 \mathrm{~kb}$ fragment of CgERG11 (nt -6 to +328 ). The signal obtained from CgER G11 was used to normalize the mRNA signals. The RNA bands that hybridized with the radiolabelled probes were visualized by autoradiography. Radiolabelling of the probe DNA was carried out by the random priming method using $\left[\alpha^{32} \mathrm{P}\right] \mathrm{dCTP}$.

Determination of cell number in vitro. Approximately $1 \times 10^{5}$ 99TEF3 cells were inoculated into YPD ( $1 \%$ yeast extract, $2 \%$ peptone, $2 \%$ glucose) containing the indicated concentrations of doxycycline $\left(0-10 \mu \mathrm{g} \mathrm{ml}^{-1}\right)$. After $14 \mathrm{~h}$ at $37^{\circ} \mathrm{C}$, the $\mathrm{OD}_{660}$ was determined. For the time-course experiments, approximately $1 \times 10^{5}$ cells of 98TOP 2 or 99TEF 3 were inoculated 
and cultured in YPD at $37^{\circ} \mathrm{C}$ with or without doxycycline (at a final concentration of $10 \mu \mathrm{g} \mathrm{ml}^{-1}$ ); their growth was monitored by measuring $\mathrm{OD}_{660}$ at the indicated times after the addition of doxycycline. The number of viable cells was also determined by spreading $20 \mu \mathrm{l}$ of the diluted cultures at the indicated times after the doxycycline addition and by counting the number of colonies that had appeared after cultivation of the cells for $24 \mathrm{~h}$ at $37^{\circ} \mathrm{C}$.

Determination of doxycycline concentration and C. glabrata cells in mouse organs. Male CD- 1 mice were immunocompromised by injecting them with $200 \mathrm{mg}$ cyclophosphamide $\mathrm{kg}^{-1} 3 \mathrm{~d}$ before infection and $100 \mathrm{mg} \mathrm{kg}^{-1} 0,3,7$ and 11 days after infection. In addition to cyclophosphamide, mice were injected with $125 \mathrm{mg}$ cortisone acetate $\mathrm{kg}^{-1}$ at the time of the cyclophosphamide injection. Each mouse was intravenously inoculated with $1 \times 10^{5} \mathrm{C}$. glabrata cells, and was administered doxycycline $\left(2 \mathrm{mg} \mathrm{ml} \mathrm{m}^{-1}\right)$, dissolved in $5 \%$ sucrose solution, as drinking water from $6 \mathrm{~d}$ before the infection. On the day indicated, the mice were killed, and their liver and kidneys were removed and homogenized in 4 vols $30 \mathrm{mM} \mathrm{H} \mathrm{PO}_{4}$ using Sonofier 250 (Branson) at $4{ }^{\circ} \mathrm{C}$. To determine the concentrations of doxycycline in each kidney and liver, $45 \mu \mathrm{l}$ of $3 \mathrm{mM}$ EDTA and $150 \mu \mathrm{l}$ of $\mathrm{CH}_{3} \mathrm{CN}$ were added to $5 \mu \mathrm{l}$ of the $20 \%$ homogenate. The resulting diluted homogenates were centrifuged at 3500 r.p.m. for $10 \mathrm{~min}$ at $4{ }^{\circ} \mathrm{C}$ and $150 \mu \mathrm{l}$ of $10 \mathrm{mM}$ phosphate solution containing $1 \mathrm{mM}$ EDTA was added to $50 \mu \mathrm{l}$ of the supernatant. The concentration of doxycycline was determined by reversephase HPLC using a Capcell pak C18 column ( $\mathrm{S}-5 \mathrm{~mm}$, $4.6 \times 150 \mathrm{~mm}$; UG $120 \mathrm{~A}$; Shiseido) in a $20 \% \mathrm{CH}_{3} \mathrm{CN}$ solution containing $8 \mathrm{mM}$ phosphate solution and $0.8 \mathrm{mM}$ EDTA. To estimate the number of surviving C. glabrata cells in kidneys, the isolated kidneys at each time point were homogenized and the homogenates spread on YPD plates containing penicillin $G$ $\left(200\right.$ units $\left.\mathrm{ml}^{-1}\right)$ and streptomycin $\left(200 \mu \mathrm{g} \mathrm{ml}^{-1}\right)$. After a $24 \mathrm{~h}$ incubation at $37^{\circ} \mathrm{C}$, the number of yeast colonies that had appeared on the plates was counted.

\section{RESULTS}

\section{Generation of a transactivator-expressing strain of C. glabrata}

To control the expression of a certain gene in $C$. glabrata, we applied the tetracycline-mediated transcription system, which we previously demonstrated in S. cerevisiae (Nagahashi et al., 1997). This system requires the controllable promoter, which consists of the tetO and ScHOP1 promoters, and the fusion transactivator, which was generated by connecting tet $R$ with S. cerevisiae GAL4AD. The transactivator gene was cloned in an integration plasmid, pINTG4, and then used to transform cells of C. glabrata strains 2001HT and 2001THU (Kitada et al., 1995), generating strains ACG4 and ACG22. Because ScHIS3 complements a his 3 null mutation of C. glabrata (Kitada et al., 1995), we first created the controllable strain 97ScHIS3 (see Methods), in which ScHIS3 was linked to the controllable promoter $97 \mathrm{t}$ (Nagahashi et al., 1997) and was integrated at the $5^{\prime}$ flanking region of the URA3 locus of ACG22, to examine whether the transactivator is functional in the transformants. When 97ScHIS3 was cultured in a histidine-depleted medium, the growth was severely impaired by the addition of tetracycline (data not shown), demonstrating that tetracycline efficiently suppressed the transcription of $S c H I S 3$ driven by the tet $\mathrm{O}:$ :ScHOP1 chimeric promoter in C. glabrata.

\section{Isolation of the C. glabrata TEF3 and TOP2 genes}

To assess the importance of certain genes for the growth and infection, we isolated the C. glabrata TEF 3 and TOP2 genes, which encode peptide elongation factor 3 and DNA topoisomerase II, respectively. As the PCR with C. glabrata genomic DNA and the primers designed from the sequence of $S$. cerevisiae YEF3 (Qin et al., 1990) yielded a single band of $0.6 \mathrm{~kb}$, this fragment was used for the further screening. After screening 2000 independent colonies, one clone termed B4, that harboured an approximately $9 \mathrm{~kb} \mathrm{BamHI}$ fragment of C. glabrata genomic DNA, was obtained. Nucleotide sequencing of $\mathrm{B} 4$ revealed that it contained a long ORF of $3.5 \mathrm{~kb}$; the amino acid sequence of the expected product is $87.4 \%$ and $78.5 \%$ identical to that of $S$. cerevisiae Yef3p and C. albicans Tef $3 p$, respectively (Table 2 ). In addition, B4 supported the growth of a YEF3-deficient $S$. cerevisiae strain (data not shown). These results demonstrate that the cloned gene is the C. glabrata homologue of $S$. cerevisiae YEF3; therefore it was designated $\mathrm{CgTEF3}$ (C. glabrata translation elongation factor 3 ).

The C. glabrata DNA topoisomerase II gene was functionally cloned using the $S$. cerevisiae top 2 temperature-sensitive mutant, SD 1-4 (DiNardo et al., 1984). By screening 20000 independent colonies, one clone which grew at a non-permissive temperature was obtained. Deletion analysis of the recovered DNA from the colony revealed that the $7 \cdot 0 \mathrm{~kb}$ Xhol-SpeI fragment was sufficient to rescue SD 1-4 at a non-permissive temperature. This fragment contained an ORF of $4.2 \mathrm{~kb}$, which can encode a protein of $161 \mathrm{kDa}$ with significant sequence identity to $S$. cerevisiae Top $2 \mathrm{p}$. We therefore designated this gene as CgTOP2 (C. glabrata DNA topoisomerase II). CgTop2p shows significant sequence homology with DNA topoisomerases from other organisms (Table 2). Among them, ScTop2p shows the highest sequence identity to CgTop2p. The tyrosine residue, which is considered to be a catalytic site in other topoisomerases (Worland \& Wang, 1989), is also conserved in CgTop2p at position 780 .

\section{Induced repression of CgTEF3 and CgTOP2}

To study the roles of TEF3 and TOP2 in growth and infection, we replaced the promoters of CgTEF3 and CgTOP2 with 97t, 98t and 99t (Nagahashi et al., 1997) by means of homologous recombination (Fig. 2a). By the transformation of each one of the above three controllable cassettes into ACG4, the five strains 98TEF3, 99TEF3, 97TOP2, 98TOP2 and 99TOP2 were generated. 97TEF3, which contains TEF3 connected to $97 \mathrm{t}$, was not obtained. The correct integration of the controllable promoters to the expected locus was confirmed by PCR using the primers C5TEF3 and C3TEF3 for TEF3, and C5TOP2 and C3TOP2 for TOP2 (Fig. 2b, c). 99TEF3 and 98TOP2 were chosen for 
Table 2. Pairwise sequence identities

Values are shown as percentage amino acid identities.

(a) Peptide elongation factor 3

\begin{tabular}{|lccc|}
\hline & S. cerevisiae* & C. albicans $\dagger$ & $\begin{array}{c}\text { Pneumocystis } \\
\text { carinit }\end{array}$ \\
\hline C. glabrata & $87 \cdot 4$ & $78 \cdot 5$ & $56 \cdot 6$ \\
S. cerevisiae & $\cdot$ & $77 \cdot 2$ & $56 \cdot 8$ \\
C. albicans & $\cdot$ & $\cdot$ & $57 \cdot 5$ \\
\hline
\end{tabular}

(b) DNA topoisomerase II

\begin{tabular}{|lcccccc|}
\hline & S. cerevisiae & C. albicans $\|$ & $\begin{array}{c}\text { Schiz. } \\
\text { pombeg }\end{array}$ & $\begin{array}{c}\text { Human } \\
\alpha \#\end{array}$ & $\begin{array}{c}\text { Human } \\
\boldsymbol{\beta} \#\end{array}$ & $\begin{array}{c}\text { Drosophila } \\
\text { melanogaster** }\end{array}$ \\
\hline C. glabrata & $73 \cdot 1$ & $56 \cdot 0$ & $48 \cdot 1$ & $48 \cdot 0$ & $42 \cdot 7$ & $41 \cdot 9$ \\
S. cerevisiae &. & $55 \cdot 9$ & $47 \cdot 7$ & $42 \cdot 0$ & $42 \cdot 0$ & $42 \cdot 1$ \\
C. albicans &. &. & $48 \cdot 5$ & $42 \cdot 6$ & $43 \cdot 3$ & $43 \cdot 1$ \\
Sch. pombe &. &. &. & $43 \cdot 6$ & $46 \cdot 6$ & $43 \cdot 4$ \\
Human $\alpha$ &. &. &. &. & $68 \cdot 1$ & $54 \cdot 1$ \\
Human $\beta$ &. &. &. &. &. & $60 \cdot 2$ \\
\hline
\end{tabular}

*Qin et al. (1990).

† Di Domenico et al. (1992) and Myers et al. (1992). $\ddagger$ Ypma-Wong et al. (1992). SGiaever et al. (1986).
|| Keller et al. (1997).

g Uemura et al. (1986).

\# Tsai-Pflugfelder et al. (1988) ( $\alpha$ ) and Jenkins et al. (1992)( $\beta)$.

** Wyckoff et al. (1989). (a)

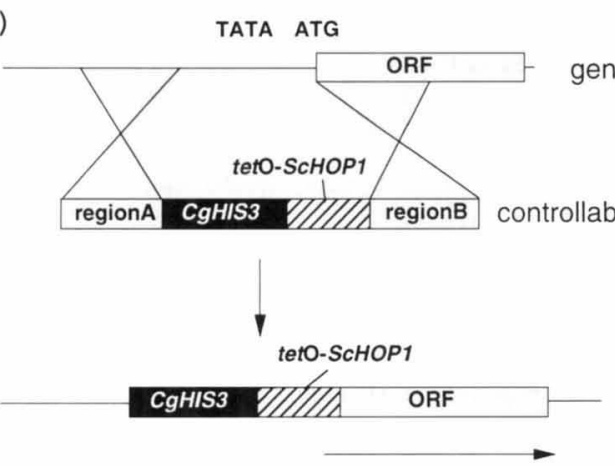

(b)

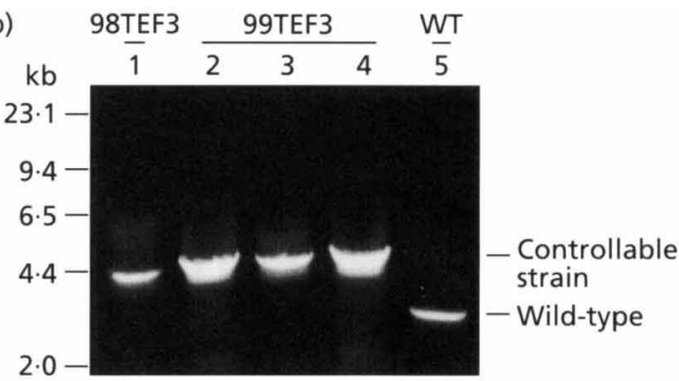

(c)

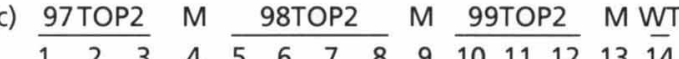

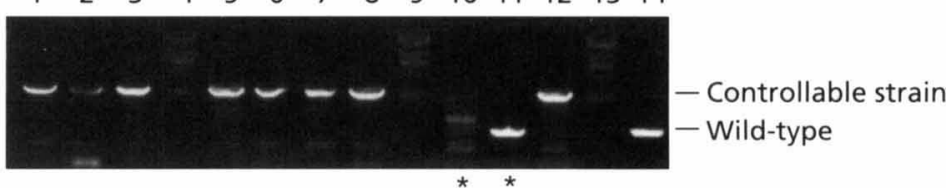

Fig. 2. Generation of controllable strains. (a) Schematic representation of the integration of the controllable promoter, tetO:: $\mathrm{SCHOP1}$. Region A represents the $5^{\prime}$ flanking region of the target gene and region $\mathrm{B}$ indicates the $5^{\prime}$ end of the ORF. The DNA fragment encompassing the controllable cassette, where the CgHIS3 gene and tetO::SCHOP1 are flanked by the $A$ and $B$ regions, was used to transform the $C$. glabrata strain ACG4. (b) Confirmation of the correct integration of the tetO::SCHOP1 in the TEF3 locus. PCR was carried out with genomic DNA from the transformants and the wild-type ATCC 2001, with the primers for the 5'-flanking region and ORF. The expected length of the PCR products for tetO::SCHOP1::TEF3 and the wild-type TEF3 are $4.6 \mathrm{~kb}$ and $2.6 \mathrm{~kb}$ respectively. Three different clones of 99TEF3 were examined. (c) Confirmation of the correct integration of tetO-SCHOP1 in the TOP2 locus. The expected length of the PCR products for tetO-ScHOP1-TEF3 and the wild-type TOP2 are $2.3 \mathrm{~kb}$ and $0.9 \mathrm{~kb}$, respectively. Lanes: 4, 9, 13, DNA size markers; $1-3$, three independent clones of 97TOP2; 5-8, four independent clones of 98TOP2; 10-12, three independent clones of 99TOP2; 14, wild-type. Asterisks indicate the random integration of tetO::SCHOP1. 
(a)

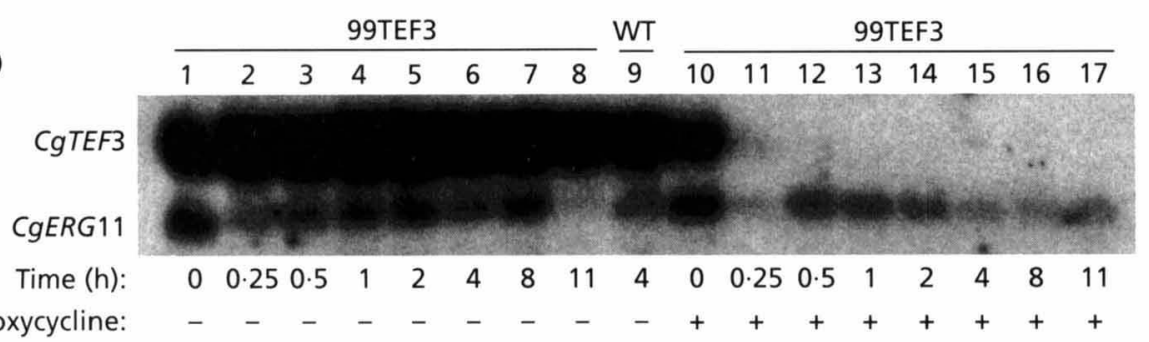

(c)

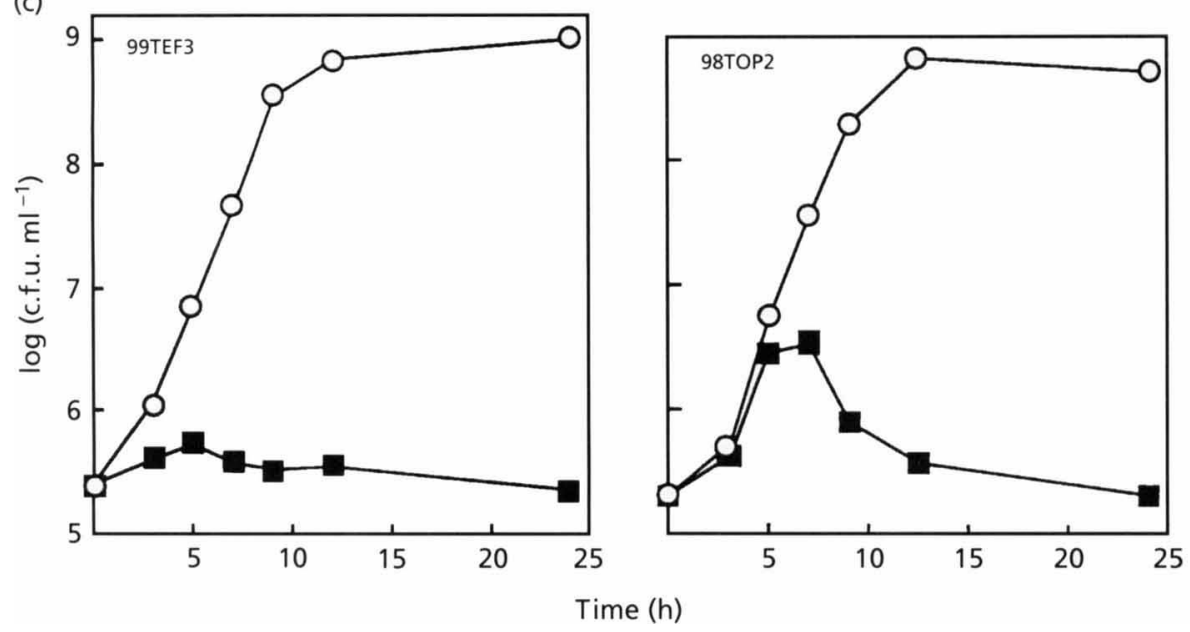

(b) $\quad \frac{97}{1} \quad \frac{W T}{2} \quad \frac{98}{3} \quad \frac{99}{5}$

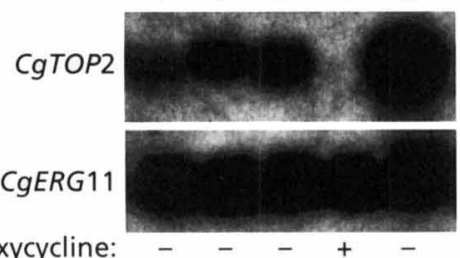

(d)

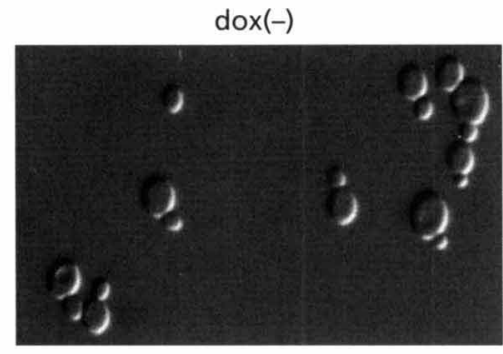

$\operatorname{dox}(+)$

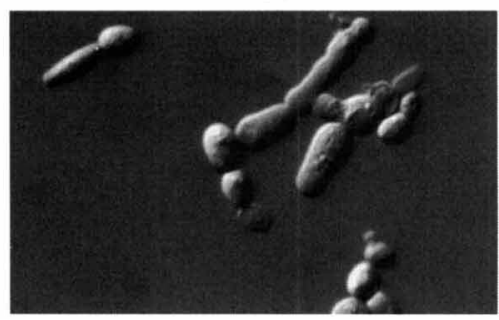

Fig. 3. Effects of doxycycline on the expression of TEF3 and TOP2 and on the growth of 99TEF3 and 98TOP2. (a) Repression of TEF3 by doxycycline. Ten million 99TEF3 cells were inoculated into YPD and cultured in the absence (lanes 1-8) or presence (lanes 10-17) of $10 \mu \mathrm{g}$ doxycycline $\mathrm{ml}^{-1}$ for the indicated time. Ten micrograms of total RNA extracted from each strain was separated on an agarose gel and hybridized with the TEF3 and ERG11 probes. Lane 9 indicates the level of the TEF3 transcript in wild-type cells. (b) Repression of TOP2 by doxycycline. Ten million cells of $98 T O P 2$ were inoculated into YPD and cultured in the presence or absence of $10 \mu \mathrm{g}$ doxycycline $\mathrm{ml}^{-1}$ for $2 \mathrm{~h}$. Ten micrograms of the total RNA extracted from each strain was separated on an agarose gel and hybridized with the TOP2 and ERG11 probes. Lanes: $1 ; 97$ TOP2; 2 , wild-type; 3 and 4, 98TOP2; 5, 99TOP2. (c) The number of viable 99TEF3 and 98TOP2 cells, cultured without $(O)$ or with $(\mathbb{}) 10 \mu \mathrm{g}$ doxycycline $\mathrm{ml}^{-1}$. (d) Morphology of 98TOP2 grown without (top) or with (bottom) $10 \mu \mathrm{g}$ doxycycline $\mathrm{ml}^{-1}$ for $12 \mathrm{~h}$.

further experiments, because they expressed the TEF3 and TOP 2 mRNAs at levels similar to those observed in the wild-type cells, and their growth in the absence of doxycycline was indistinguishable from that of the wildtype (Fig. 3a, lanes 1-8 for 99TEF3, lane 9 for wild-type; and Fig. 3b, lane 1 for 97TOP2, lane 2 for wild-type, lane 3 for 98TOP2, lane 5 for 99TOP2). We used doxycycline instead of tetracycline, because it was superior to tetracycline in terms of suppressing the expression of TEF3 and TOP2 (data not shown). By Northern blotting, it was demonstrated that the TEF3 mRNA declined to an undetectable level within $30 \mathrm{~min}$ of the addition of doxycycline (Fig. 3a, lanes 12-17). The TOP2 mRNA also became undetectable within $2 \mathrm{~h}$ of doxycycline addition (Fig. 3b, lane 4). In contrast, doxycycline did not significantly affect the level of lanosterol 14-demethylase (ERG11 gene) mRNA, indicating the specificity of doxycycline to the tet $\mathrm{O}: \mathrm{ScHOP}$ 1 promoter (Fig. 3a, b). Seven hours after doxycycline addition, the 98TOP2 cells displayed aberrant morphology and the number of viable cells started decreasing (Fig. 3c). Most of the 98TOP2 cells became elongated and aggregated within $12 \mathrm{~h}$ (Fig. 3d). The growth of the 99TEF3 cells was also severely hampered by doxycycline; the number of viable cells remained very small at any time after the doxycycline addition (Fig. 3c). However, we did not observe any morphological changes in 99TEF3 cells, even when they were cultured in the presence of doxycycline. The growth impairment of 99TEF3 by doxycycline was reproducibly observed at doxycycline concentrations higher than $2 \mu \mathrm{g}$ $\mathrm{ml}^{-1}$ (Fig. 4a); the same result was obtained with 98TOP2 cells (data not shown). Together, these results demonstrate that both TEF3 and TOP 2 are essential for the growth of C. glabrata, and that the depletion of TEF3 leads to immediate cell death, while the effect of TOP2 repression on viability becomes apparent after several generations. 
(a)

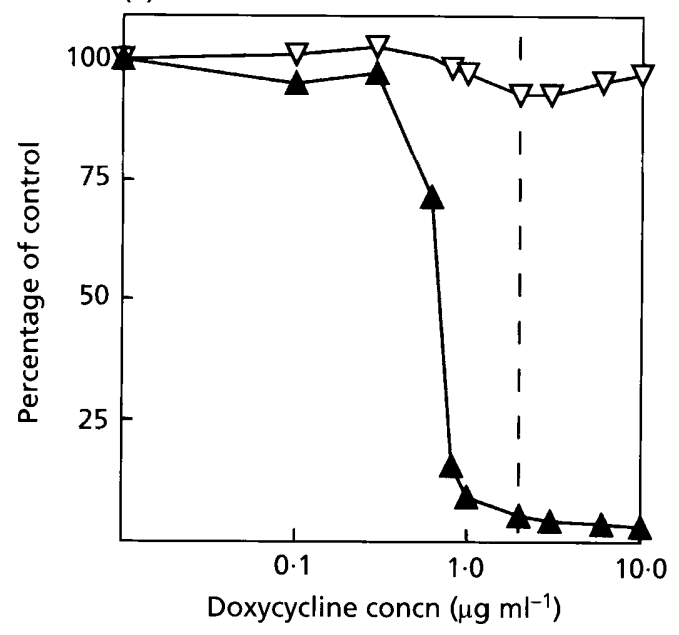

(b)

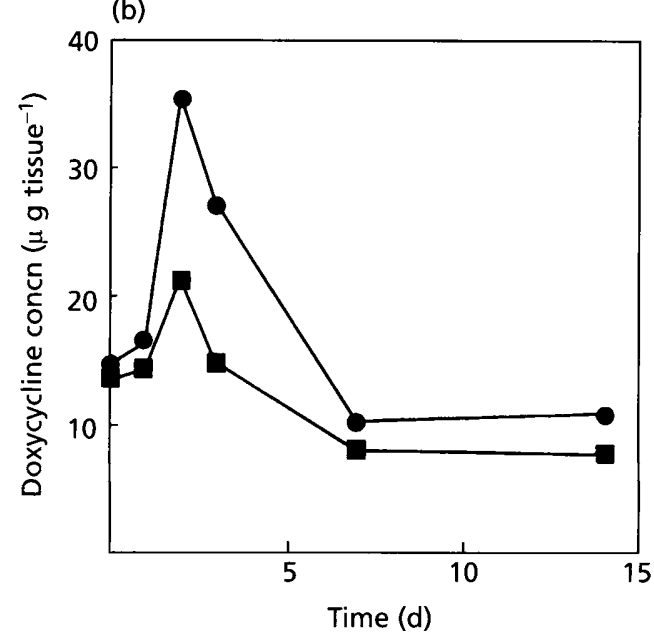

(c)
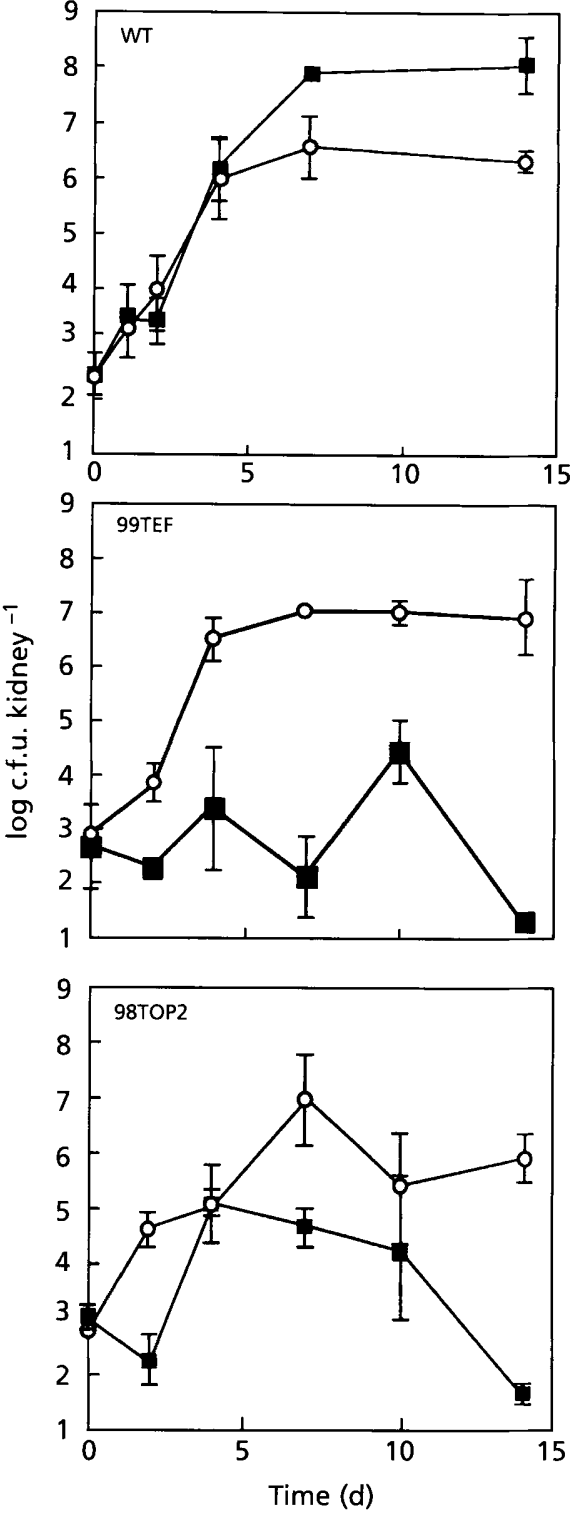

Fig. 4. Effects of doxycycline on the survival of 99TEF3 and $98 T O P 2$ in mouse kidneys. (a) Determination of the minimal concentrations of doxycycline required to inhibit the growth of 99TEF3. One hundred thousand 99TEF3 cells were inoculated into YPD and cultured for $14 \mathrm{~h} . \mathrm{OD}_{660}$ is indicated as the percentages of those of doxycycline-untreated cells. Each value is the mean from three independent experiments. $\boldsymbol{\Delta}$, TEF3 cells; $\nabla$, wild-type cells. (b) Concentrations of doxycycline in liver ( $)$ and kidneys $(\boldsymbol{D})$ of the immunocompromised mice. Each value is the mean from the three independent experiments. (c) Number of viable cells recovered from mouse kidneys. Mice that were infected with wildtype (top), 99TEF3 (middle) and 98TOP2 (bottom) were killed, and the C. glabrata cells were recovered from the kidneys. Error bars indicate standard deviation from three independent kidneys. Experiments were repeated three times. $O$, Number of cells recovered from doxycycline-untreated mice; $\boldsymbol{\square}$, number of cells recovered from doxycycline-treated mice. Error bars are not shown where the symbol is bigger than the error bar.

\section{Effects of TEF3 and TOP2 repression on the survival of C. glabrata in mice}

Next, we intended to establish the roles of TEF3 and TOP2 on the survival of C. glabrata in mice. As mentioned earlier, expression of CgTEF3 and TOP2 was almost completely repressed by $2 \mu \mathrm{g} \mathrm{ml}^{-1}$ or higher concentrations of doxycycline. When doxycycline was added to the drinking water and the mice were allowed to drink freely from $6 \mathrm{~d}$ prior to infection, the doxycycline concentrations reached $8 \mu \mathrm{g}(\mathrm{g} \text { kidney })^{-1}$ and $10 \mu \mathrm{g}(\mathrm{g} \text { liver })^{-1}$, which are higher than the minimum concentration of doxycycline required to suppress TEF3 and TOP2 expression in vitro (Fig. $4 \mathrm{~b}$ ). Then, the number of viable C. glabrata cells in kidneys was determined by recovering the C. glabrata cells at various times after infection, because the C. glabrata cells exclusively colonized the kidneys (data not shown). The 
number of viable 99TEF3 and 98TOP2 cells recovered from the kidneys was significantly lower in mice treated with doxycycline than in untreated mice. Although there was a transient increase in the number of recovered cells at 4 and $10 \mathrm{~d}$ post-infection, essentially 99TEF 3 did not grow in mouse kidneys when doxycycline was present. The number of viable 98TOP2 cells increased up to day 4 , which was followed by a rapid decline from day 10 . The profiles of the doxycycline-mediated decrease in the number of viable 99TEF3 and 98TOP2 cells in the kidneys were similar to those of doxycycline-induced growth inhibition in vitro. Thus, it appears that the functions of TEF3 and TOP2 for viability are well preserved not only in cultures in vitro, but also in the organs of infected animals.

\section{DISCUSSION}

We have established a controllable gene expression system in C. glabrata. Doxycycline almost completely suppressed the expression of a gene whose transcription was under the control of the tetO::ScHOP1 promoter. Furthermore, transcriptional repression of the gene by doxycycline occurred relatively quickly. The TEF3 and TOP2 mRNA declined to an undetectable level within $2 \mathrm{~h}$ of the addition of doxycycline. The rapid response to doxycycline enabled us to study the roles of these genes in the survival of C. glabrata cells in animals.

By the doxycycline-induced repression, it appears that the effect of $T E F 3$ depletion occurred much earlier than that of TOP2. Because TEF3 repression would lead to a serious defect in protein synthesis, it might cause a rapid arrest of the cell growth. 98TEF3, which expressed a lower level of the TEF3 mRNA, showed a slight growth defect even in the absence of doxycycline (data not shown). This fact implies that proper levels of TEF3 mRNA must be maintained to keep C. glabrata cells alive. The TOP2 depletion, however, affected cell growth only after several generations. This is rather an unexpected result, because Top2p is required for the completion of DNA replication and for the segregation of sister chromatids. A defect in either one of these steps may result in rapid cell death. The results obtained from this study, however, suggest that inhibition of protein synthesis more effectively causes rapid cell death than that of DNA replication.

When TOP2 was repressed, C. glabrata cells displayed an elongated morphology (Fig. 3c). A similar phenotype was also observed in the temperature-sensitive mutants of S. cerevisiae and Schizosaccharomyces pombe when they were cultured at a non-permissive temperature (DiNardo et al., 1984; Holm et al., 1985; Uemura \& Yanagida, 1986). The aberrant morphology caused by a top2 mutation has been reported to be associated with the appearance of abnormal chromosomes. Therefore, the elongated morphology caused by doxycycline in 98TOP2 cells is probably a consequence of the inhibition of DNA topoisomerase II.
The effects of doxycycline on the cell growth of 99TEF3 and 98TOP2 in vitro were well reflected in animal organs. This indicates that the physiological importance of TEF3 and TOP2 is not dependent on the conditions in which C. glabrata grows. Thus, this system can be applied to other genes whose function remains to be elucidated and also to the identification of novel virulence factors.

\section{ACKNOWLEDGEMENTS}

We thank A. Kikuchi (Nagoya University) for the S. cerevisiae strain SD 1-4, S. Ichihara for HPLC analysis, N. Kawamura for DNA sequencing and $\mathrm{H}$. Okabe for critically reading the manuscript.

\section{REFERENCES}

Aisner, J., Schimpff, S. C., Sutherland, J. C., Young, V. M. \& Wiernik, P. H. (1976). Torulopsis glabrata infections in patients with cancer: increasing incidence and relationship to colonization. Am J Med 61, 23-28.

Barns, S. M., Lane, D. J., Sogin, M. L., Bibeau, C. \& Weisburg, W. G. (1991). Evolutionary relationships among pathogenic Candida species and relatives. J Bacteriol 173, 2250-2255.

DiNardo, S., Voelkel, K. \& Sternglanz, R. (1984). DNA topoisomerase II mutant of Saccharomyces cerevisiae: topoisomerase II is required for segregation of daughter molecules at the termination of DNA replication. Proc Natl Acad Sci USA 81, 2616-2620.

Di Domenico, B. J., Lupisella, J., Sandbaken, M. \& Chakraburtty, K. (1992). Isolation and sequence analysis of the gene encoding translation elongation factor 3 from Candida albicans. Yeast 8 , 337-352.

Figgitt, D. P., Denyer, S.P., Dewick, P. M., Jackson, D. E. \& Williams, P. (1989). Topoisomerase II : a potential target for novel antifungal agent. Biochem Biophys Res Commun 160, 257-262.

Gallis, H. A., Drew, R. H. \& Pickard, W. W. (1990). Amphotericin B: 30 years of clinical experience. Rev Infect Dis 12, 308-329.

Georgopapadakou, N. H. \& Walsh, T. J. (1996). Antifungal agents: chemotherapeutic targets and immunologic strategies. Antimicrob Agents Chemother 40, 279-291.

Giaever, G., Lynn, R., Goto, T. \& Wang, J. C. (1986). The complete nucleotide sequence of the structural gene TOP2 of yeast DNA topoisomerase II. J Biol Chem 261, 12448-12454.

Goto, T. \& Wang, J. C. (1984). Yeast DNA topoisomerase II is encoded by a single-copy, essential gene. Cell 36, 1073-1080.

Hickey, W. F., Sommerville, L. H. \& Schoen, F. J. (1983). Disseminated Candida glabrata - report of a uniquely severe infection and a literature review. Am J Clin Pathol 80, 724-727.

Hitchcock, C. A., Pye, G. W., Troke, P. F., Johnson, E. M. \& Warnock, D.W. (1993). Fluconazole resistance in Candida glabrata. Antimicrob Agents Chemother 37, 1962-1965.

Holm, C., Goto, T., Wang, J. C. \& Botstein, D. (1985). DNA topoisomerase II is required at the time of mitosis in yeast. Cell 41 , 553-563.

Jenkins, J. R., Ayton, P., Jones, T., Davies, S. L., Simmons, D. L., Harris, A. L., Sheer, D. \& Hickson, I. D. (1992). Isolation of cDNA clones encoding the beta isozyme of human DNA topoisomerase II and localization of the gene to chromosome $3 \mathrm{p} 24$. Nucleic Acids Res 20, 5587-5592. 
Kitada, K., Yamaguchi, E. \& Arisawa, M. (1995). Cloning of the Candida glabrata TRP1 and HIS3 genes, and construction of their disruptant strains by sequential integrative transformation. Gene 165, 203-206.

Keller, B. A., Patel, S. \& Fisher, L. M. (1997). Molecular cloning and expression of the Candida albicans TOP2 gene allows study of fungal DNA topoisomerase II inhibitors in yeast. Biochem J 324, 329-339.

Myers, K. K., Fonzi, W. A. \& Sypherd, P. S. (1992). Isolation and sequence analysis of the gene for translation elongation factor 3 from Candida albicans. Nucleic Acids Res 20, 1705-1710.

Nagahashi, S., Nakayama, H., Hamada, K., Yang, H., Arisawa, M. \& Kitada, K. (1997). Regulation by tetracycline of gene expression in Saccharomyces cerevisiae. Mol Gen Genet 273, 372-375.

Newman, S. L., Flanigan, T. P., Fisher, A., Rinaldi, M. G., Stein, M. \& Vigilante, K. (1994). Clinically significant mucosal candidiasis resistant to fluconazole treatment in patients with AIDS. Clin Infect Dis 19, 684-686.

Qin, S. L., Xie, A. G., Bonato, M. C. \& McLaughlin, C. S. (1990). Sequence analysis of the translation elongation factor 3 from Saccharomyces cerevisiae. J Biol Chem 265, 1903-1912.

Rex, J. H., Rinaldi, M. G. \& Pfaller, M. A. (1995). Resistance of Candida species to fluconazole. Antimicrob Agents Chemother 39, 1-8.

Rose, M. D., Winston, F. \& Hieter, P. (1990). Methods in Yeast Genetics. Cold Spring Harbor, NY: Cold Spring Harbor Laboratory.

Sandbaken, M. G., Lupisella, J. A., DiDomenico, B. \& Chakraburtty, K. (1990). Protein synthesis in yeast. Structural and functional analysis of the gene encoding elongation factor 3. $J$ Biol Chem 265, 15838-15844.

Shen, L. L., Baranowski, J., Fostel, J., Montgomery, D. A. \& Lartey, P. A. (1992). DNA topoisomerases from pathogenic fungi: targets for the discovery of antifungal drugs. Antimicrob Agents Chemother 36, 2778-2784.

Triana-Alonso, F. J., Chakraburtty, K. \& Nierhaus, K. H. (1995).
The elongation factor 3 unique in higher fungi and essential for protein biosynthesis is an E site factor. J Biol Chem 270, 20473-20478.

Tsai-Pflugfelder, M., Liu, L. F., Liu, A. A., Tewey, K. M., WhangPeng, J., Knutsen, T., Huebner, K., Croce, C. M. \& Wang, J. C. (1988). Cloning and sequencing of $\mathrm{cDNA}$ encoding human DNA topoisomerase II and localization of the gene to chromosome region 17q21-22. Proc Natl Acad Sci USA 85, 7177-7181.

Uemura, T. \& Yanagida, M. (1986). Mitotic spindle pulls but fails to separate chromosomes in type II DNA topoisomerase mutants: uncoordinated mitosis. EMBO J 5, 1003-1010.

Uemura, T., Morikawa, K. \& Yanagida, M. (1986). The nucleotide sequence of the fission yeast DNA topoisomerase II gene: structural and functional relationships to other DNA topoisomerases. EMBO J. 5, 2355-2361.

Vershon, A. K., Hollingsworth, N. M. \& Johnston, A. D. (1992). Meiotic induction of the yeast HOP1 gene is controlled by positive and negative regulatory sites. Mol Cell Biol 12, 3706-3714.

Wingard, J. R. (1995). Importance of Candida species other than C. albicans as pathogens in oncology patients. Clin Infec Dis 115, 115-125.

Worland, S. T. \& Wang, J. C. (1989). Inducible overexpression, purification, and active site mapping of DNA topoisomerase II from the yeast Saccharomyces cerevisiae. J Biol Chem 264, $4412-4416$

Wyckoff, E., Natalie, D., Nolan, J. M., Lee, M. \& Hsieh, T. (1989). Structure of the Drosophila DNA topoisomerase II gene. Nucleotide sequence and homology among topoisomerases II. J Mol Biol 205, 1-13.

Ypma-Wong, M. F., Fonzi, W. A. \& Sypherd, P. S. (1992). Fungusspecific translation elongation factor 3 gene present in Pneumocytis carinii. Infect Immun 60, 4140-4145.

Received 26 March 1998; revised 29 May 1998; accepted 8 June 1998. 